\title{
Coat Protein Gene-Mediated Resistance to Soybean Mosaic Virus in Transgenic
} Soybean

\author{
Noriyuki Furutani*1), Soh Hidaka ${ }^{2)}$, Yoshitaka Kosaka1), Yoshiaki Shizukawa ${ }^{1)}$ and Seiji Kanematsu' ${ }^{2)}$ \\ 1) Kyoto Prefectural Institute of Agricultural Biotechnology, 74 Oaza Kitaina Yazuma, Seika, Soraku, Kyoto 619-0244, Japan \\ 2) National Agricultural Research Center for Tohoku Region, 4 Akahira, Shimokuriyagawa, Morioka, Iwate 020-0198, Japan
}

\begin{abstract}
Somatic embryos of Glycine max (L.) Merrill cultivar 'Jack' were co-transformed with coat protein (CP) gene of attenuated isolates of soybean mosaic virus (SMV) and hygromycin phosphotransferase (hpt) gene by means of microprojectile bombardment. These transformed embryogenic tissues were selected in hygromycincontaining liquid medium. The hygromycin-resistant embryogenic tissues obtained through the selection were regenerated, and $\mathrm{CP}$ gene was detected in the 11 transgenic plants out of them. In order to assess their resistance to SMV, mechanical inoculation was performed in $T_{1}$ generation. The disease symptom was examined visually and confirmed by the enzyme-linked immunosorbent assay (ELISA). Finally we obtained three independent lines highly resistant to SMV. This is the first report of the soybean plants that were conferred a high resistance to SMV by the transformation with CP gene of the SMV attenuated isolates. In these three lines, the presence of transgene transcript was confirmed by Northern blot analysis, and the transgene product was detected in two of them by Western blot analysis.
\end{abstract}

Key Words: Glycine max, coat protein gene-mediated resistance, attenuated isolates of soybean mosaic virus, microprojectile bombardment.

\section{Introduction}

Soybean mosaic virus (SMV) belongs to the genus Potyvirus and contains a single-stranded positive sense RNA encapsidated by a single coat protein (CP). The infection of SMV is observed commonly in almost all of the soybean producing areas over the world. The inoculum source originates from infected plants that emerge from the infected seeds, and spreads through the activity of numerous aphid species. This makes the perfect control of this virus disease difficult. When SMV infects young soybean plants, it causes a reduction of pod sets, an increase of seed coat mottling, and losses of seed size and weight. On the other hand, lateseason infection has little effect on the seed quality and yield. SMV infection also reduces the oil content and nodulation, affects the nitrogen fixation, and reduces the seed germinability (Sinclair 1984).

Normally the strategies for the management of viral diseases include the use of virus-free propagation material or resistant cultivars by traditional breeding, as well as the inoculation of the attenuated virus (Jules 1994, Namba 1992, Scholthof et al. 1993). Although traditional breeding methods for virus resistance have delivered new resistant cultivars, the process is labor intensive and time consuming. Also, they are often accompanied by undesirable traits which

Communicated by S. Nishimura

Received May 2, 2005. Accepted November 28, 2005.

*Corresponding author (e-mail: nfurutani@kab.seika.kyoto.jp) must be selected out in order for a new variety to be commercially acceptable. (Namba 1992, Hadidi et al. 1998). On the other hand, owing to the recent advanced technology in molecular biology, the pathogen-derived resistance (PDR) has been successfully developed to confer resistance against viruses in many crop plants effectively.

PDR is the outcome of a process of transforming a plant with a gene from a pathogen, in order to endow the plant the resistance to the pathogen (Sanford and Johnson 1985). The viral CP gene is the first and one of the most widely used genes to confer PDR against plant viruses (Powell-Abel et al. 1986). Actually the successful application of CP genemediated resistance to several crops has been reported (Fitchen and Beachy 1993).

In spite of the many cases of applying PDR to the crop species, only two successful applications have been reported in soybean. The first successful PDR application to soybean was the transformation of soybean plants with $\mathrm{CP}$ gene of bean pod mottle virus (BPMV) G-7 strain, which gave them a complete resistance to BPMV (Rong et al. 1996). The second was the Agrobacterium tumefaciens-mediated transformation with CP gene of SMV N strain, which confirmed the high resistance to SMV in the fixed lines. (Wang et al. 2001).

In our study, we adopted the CP gene of the attenuated isolates from SMV (Kosaka and Fukunishi 1993) as a mediator of PDR, and introduced it into soybean by the microprojectile bombardment method.

Attenuated isolate of SMV (designated as Aa15-M2) 
was obtained by the low temperature treatment of the original Aa isolate, and produced moderate symptoms when infecting soybean plants. However, Aa15-M2 was protective against the attack of five standard strains A, B, C, D and E of SMV (Shigemori 1991), and has been commonly used to confer SMV resistance to black soybean (Glycine max cv. Shin Tambaguro) in Kyoto Prefecture, Japan.

CP gene of this Aa15-M2 and hpt gene were introduced into soybean by the co-transformation method developed previously (Furutani and Hidaka 2004).

We describe the process of establishing the pathogen resistance by the genetic engineering with $\mathrm{CP}$ gene of the attenuated pathogen.

\section{Materials and Methods}

\section{Plasmid construction}

The CP gene of SMV attenuated isolate (Aa15-M2) was obtained from the total RNA from the infected leaves by RT-PCR. Primers were designed for the amplification of $\mathrm{CP}$ coding region (nucleotide No. 8538-9335): of the viral genome (DDBJ accession No. AB100443). The forward primer $\quad\left(5^{\prime}\right.$-AATCTAGAATGTCAGGCAAGGAGAAG-3') contains $X b a \mathrm{I}$ restriction site with the initiation codon ATG, and the reverse one (5'-TTGAGCTCTTACTGCGGTGGGCC $\left.C A T-3^{\prime}\right)$ carries $S a c$ I restriction site, respectively. The amplified product was digested with each restriction enzyme and cloned into the corresponding site of pE2113 vector (Mitsuhara et al. 1996) (Fig. 1). The plasmid containing hpt gene for a selectable marker, pE2113-HPT, was also used as described previously (Furutani and Hidaka 2004).

\section{Transformation}

We used Glycine max (L.) Merrill cv. 'Jack', whose somatic embryos are comparatively easy to induce cultures (Samoylov et al. 1998). Culture initiation and proliferation of embryos followed the methods of Finer and Nagasawa (1988). Immature cotyledons less than $10 \mathrm{~mm}$ in size were placed adaxial side down on MSD40 solid medium, and embryos were proliferated for 9 weeks with 2 transfers at intervals of 3 weeks. The globular embryo clusters were selected and transferred to MSD20 solid medium. The culture conditions were at $25^{\circ} \mathrm{C}$ and a 16 -h photoperiod with light in- tensity of $5 \mu \mathrm{mol} \mathrm{m}^{-2} \mathrm{~s}^{-1}$.

Co-transformation by microprojectile bombardment, selection, and regeneration were performed as described previously (Furutani and Hidaka 2004).

\section{PCR and Southern blot hybridization analysis}

As the first step to determine the presence of CP gene in regenerated hygromycin-resistant plants, DNA was extracted from leaves of putative transformants and nontransformed plants (50 mg fresh weight), using the Qiagen DNeasy kit according to the manufacturer's directions. Integration of CP gene into the soybean genome was verified by PCR analysis using $\mathrm{CP}$ gene-specific primers [forward (5'-ATG TCA GGC AAG GAG AAG GAA G-3') and reverse (5'-TTA CTG CGG TGG GCC CAT GC-3')], which were designed to amplify ca $800 \mathrm{bp}$ fragment including the coding region. Conditions for the thermal cycle were: step $1: 92^{\circ} \mathrm{C}$ (5 min); step 2 ( 30 cycles): $92^{\circ} \mathrm{C}(1 \mathrm{~min}), 61^{\circ} \mathrm{C}(2 \mathrm{~min}), 72^{\circ} \mathrm{C}$ (2 min); and step $3: 72^{\circ} \mathrm{C}(7 \mathrm{~min})$.

For Southern blot analysis, DNA was extracted from young leaves of $T_{1}$ plants (100 $\mathrm{mg}$ fresh weight), using the Qiagen DNeasy kit according to the manufacturer's directions. Following the digestion with HindIII, $5 \mu \mathrm{g}$ of DNA was electrophoresed through a $1.0 \%$ agarose gel, and blotted onto a nylon membrane Hybond-N+ (Amersham Pharmacia Biotech UK Ltd.). Labeling of the PCR-amplified CP sequence containing the whole coding region as a probe, hybridization, and detection were performed using the 'Alkphos Direct Labeling Kit' and the 'Detection System with CDP-Star' (Amersham Pharmacia Biotech UK Ltd.) according to the instruction manual.

\section{Mechanical inoculation}

The seeds of transformant and non-transformant were sown in a greenhouse in which the temperature was kept at $25^{\circ} \mathrm{C}$. Ten days after seeding, the primary leaves of 10 nontransformants were mechanically inoculated with the attenuated SMV (Kosaka and Fukunishi 1993). Mechanical inoculation was carried out by rubbing leaves with cotton swabs dipped in the mixture of carborundum and the extract of infected leaves ground in approximately 50 volumes $(\mathrm{ml} / \mathrm{g})$ of $0.1 \mathrm{M}$ phosphate buffer ( $\mathrm{pH}$ 7.2). After the inoculation, the leaves were rinsed with tap water.

\section{pE2113 -SMV-CP}

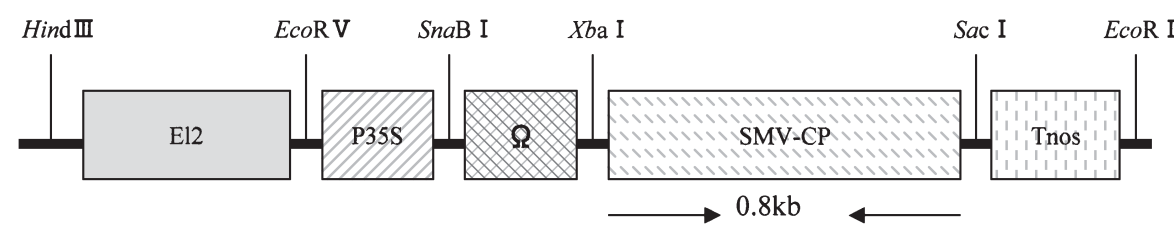

Fig. 1. Restriction map of pE2113-SMV-CP. SMV-CP: gene encoding SMV coat protein, El2: 5' upstream sequence of the CaMV $35 \mathrm{~S}$ promoter $\mathrm{x} 2, \Omega$ : 5'-untranslated sequence of TMV, P35S: CaMV 35S promoter, Tnos: polyadenylation signal of the nopaline synthase gene of Agrobacterium tumefaciens $\mathrm{T}_{\mathrm{i}}$ plasmid. 
Mechanical inoculation of SMV standard strain A or D was carried out separately on the leaves of transformants non-transformants and non-transformants that were inoculated with attenuated SMV previously ( 8 days before). The condition of the mechanical inoculation was the same as mentioned above.

They were kept in a greenhouse and were visually examined weekly for 28 days after the inoculation to discern the appearance of symptoms. As SMV symptoms are sometimes difficult to discern, the ELISA (Tsuchizaki and Omura 1987) was carried out 28 days after the inoculation to confirm the SMV resistance of the symptom-free leaves.

\section{Analysis of gene expression}

Northern blot analysis was carried out to detect the CP gene transcripts in the transformants. Total soybean RNA was isolated from young leaves $(0.08 \mathrm{~g})$ using TRIZOLreagent (GIBCO BRL) according to the instruction manual. Ten $\mu$ g of each sample was separated on a $1.5 \%$ agarose gel containing $30 \%$ formaldehyde, and transferred onto a nylon membrane (Amersham Pharmacia Biotech UK Ltd.). PCRamplified CP sequence was labeled, and hybridization and detection of RNA were carried out as described above.

Western blot analysis was also carried out to detect the presence of transgene product in the transformants. The total soybean protein was extracted in the buffer containing 250 $\mathrm{mM}$ Tris (pH 7.5), $2.5 \mathrm{mM}$ EDTA, $0.1 \%$ ascorbic acid and 1 $\mathrm{mM}$ phenyl-methyl-sulphonyl fluoride (PMSF, Sigma). The homogenates were then centrifuged for $10 \mathrm{~min}$ at $10,000 \mathrm{~g}$. Prior to the loading, the resulting pellets were boiled for 5 min in a buffer containing $40 \mathrm{mM}$ Tris- $\mathrm{HCl}$ (pH 6.8), 4\% SDS, 4\% 2-mercaptoethanol, 20\% glycerol and $0.02 \%$ bromo-phenolblue. The proteins were separated by SDSpolyacrylamide gel electrophoresis by the discontinuous
Laemmli system (Laemmli 1970) (5.0\% acrylamide stacking gel and $12.5 \%$ acrylamide separation gel). The separated proteins were electrotransferred onto a nitrocellulose membrane (Amersham Pharmacia Biotech UK Ltd.). The blot was incubated in SMV-CP specific rabbit antiserum IgG. After being washed, it was again incubated in a 1/5000 dilution of the goat anti-rabbit antibody conjugated with alkaline phosphatase. The reaction product was detected by NBT/BCIP (Life Technologies, Princeton, NJ).

\section{Results}

\section{Transformant analysis}

Among the 121 transgenic soybean plants, 11 plants were ascertained by PCR to have been introduced with $\mathrm{CP}$ gene of SMV attenuated isolates. They grew normally, flowered, and set seeds.

All the non-transformants were infected by 14 days after the inoculation, while non-transformants inoculated with the attenuated SMV revealed to be conferred resistance. Among 11 transgenic soybean plants, Nos. 10, 58, 60, 68 and 82 were infected by 14 days after the inoculation. In transgenic soybean plants Nos. 32, 33 and 79, no symptoms were observed by 14 days after the inoculation, but were infected later by 28 days.

Ten transformed $\mathrm{T}_{1}$ plants of the No. 55, 7 plants of the No. 86 and 1 plant of the No. 118 showed no symptoms by 28 days after the inoculation (Table 1, Fig. 2A). In these plants, SMV was not detected by ELISA (data not shown), and the resistance was ascertained.

Southern blot hybridization analysis of Nos. 55, 86 and 118 showed that they were originated from different events and 6 copies of $C P$ gene were contained in resistant $T_{1}$ plants of the No. 55, 4 in the No. 86 and 2 in the No. 118 (Fig. 3).

Table 1. Response of $\mathrm{T}_{1}$ plants with CP-transgene at 14 and 28 days post inoculation

\begin{tabular}{|c|c|c|c|c|}
\hline \multirow{2}{*}{ Transgenic soybean plants No. } & \multirow{2}{*}{$\begin{array}{c}\text { Number of } \\
\text { plants evaluated }\end{array}$} & \multirow{2}{*}{$\begin{array}{l}\text { Number of plants } \\
\text { with transgene }\end{array}$} & $14 \mathrm{dpi}^{11}$ & \multirow{2}{*}{$\begin{array}{c}\text { 28dpi } \\
\text { Number of resistant plants }\end{array}$} \\
\hline & & & Number of resistant plants ${ }^{3)}$ & \\
\hline 10 & 4 & 2 & 0 & - \\
\hline 32 & 9 & 6 & 2 & 0 \\
\hline 33 & 12 & 9 & 1 & 0 \\
\hline 55 & 39 & 31 & 11 & 10 \\
\hline 58 & 21 & 7 & 0 & - \\
\hline 60 & 30 & 20 & 0 & - \\
\hline 68 & 24 & 11 & 0 & - \\
\hline 79 & 16 & 10 & 2 & 0 \\
\hline 82 & 26 & 16 & 0 & - \\
\hline 86 & 22 & 11 & 7 & 7 \\
\hline 118 & 7 & 4 & 1 & 1 \\
\hline $\begin{array}{l}\text { Non-transformant inoculated } \\
\text { with attenuated isolates }\end{array}$ & 24 & - & 24 & 24 \\
\hline Non-transformant & 25 & - & 0 & - \\
\hline \multicolumn{5}{|c|}{ 1) Days post inoculation } \\
\hline \multicolumn{5}{|c|}{ 2) Presence of transgene was comfirmed by polymerase chain reaction (PCR). } \\
\hline \multicolumn{5}{|c|}{ 3) Resistant plants were those that showed no symptoms. } \\
\hline
\end{tabular}



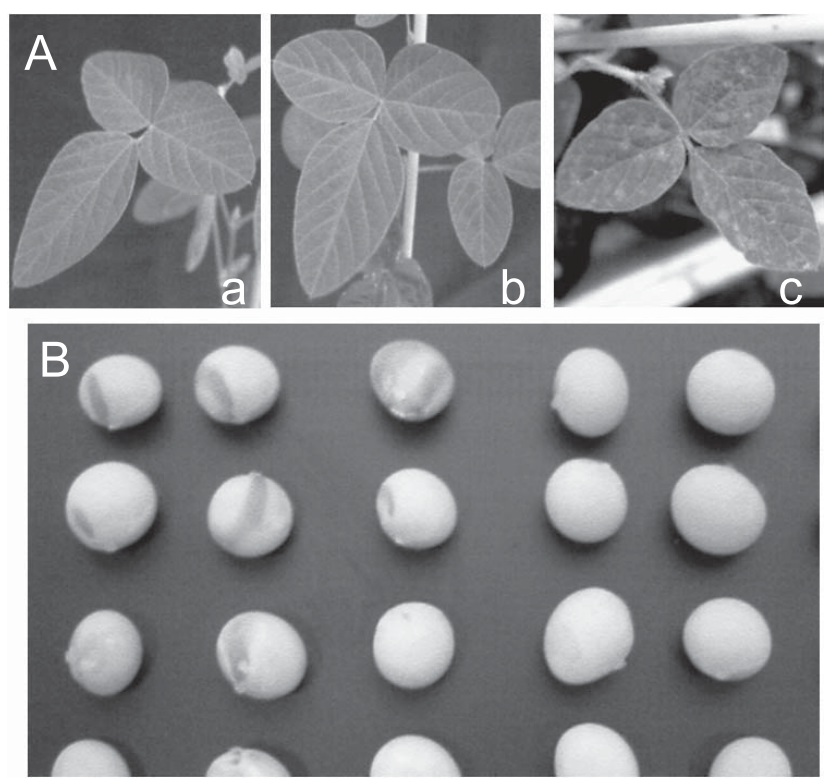

Fig. 2. A: Response of transgenic plants to inoculation with SMV (strain-D). (a) Transgenic line No. 55-10, (b) Transgenic line No. 86-10, (c) Non-transformed plant (cv. Jack) was showing severe symptom. B: Soybean seed harvested from SMV strain D-inoculated plants of transgenic line No.55-10 (right) and the susceptible non-transformed (left).

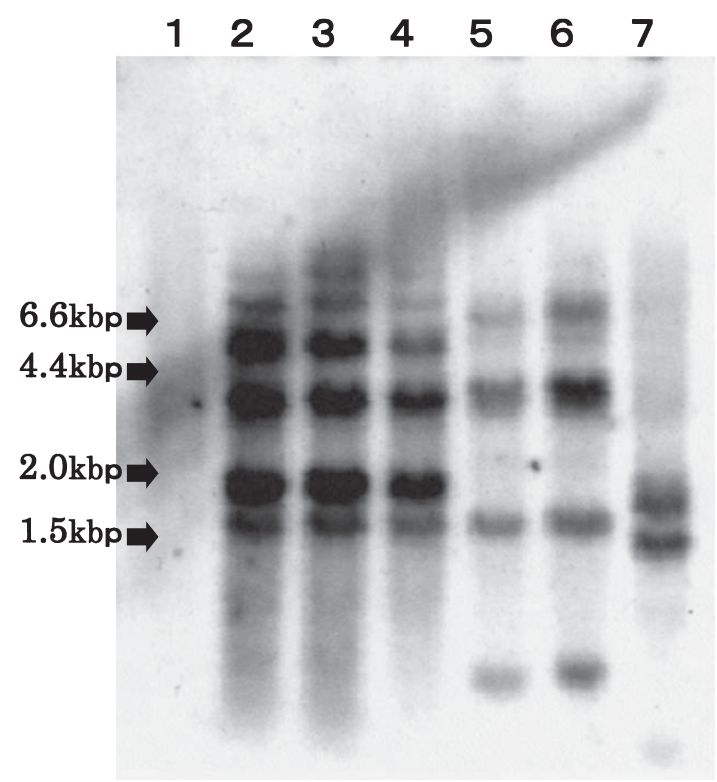

Fig. 3. Southern blot analysis of HindIII-digested total DNA probed with a $\mathrm{CP}$ fragment in transformed plants. Lane 1: nontransformed plant (cv. Jack); lanes 2-4: 3 plants from No. 55; lanes 5 and 6: 2 plants from No. 86; lane 7: one plant from No.118. DNA size markers are shown on the left.

The SMV-resistant transformants grew normally, and set seeds. Among the seeds harvested from the SMVresistant plants, mottling of seed coat was less than $2 \%$, in contrast to $80 \%$ of those seeds harvested from the nontransformant SMV-infected plants (Fig. 2B).

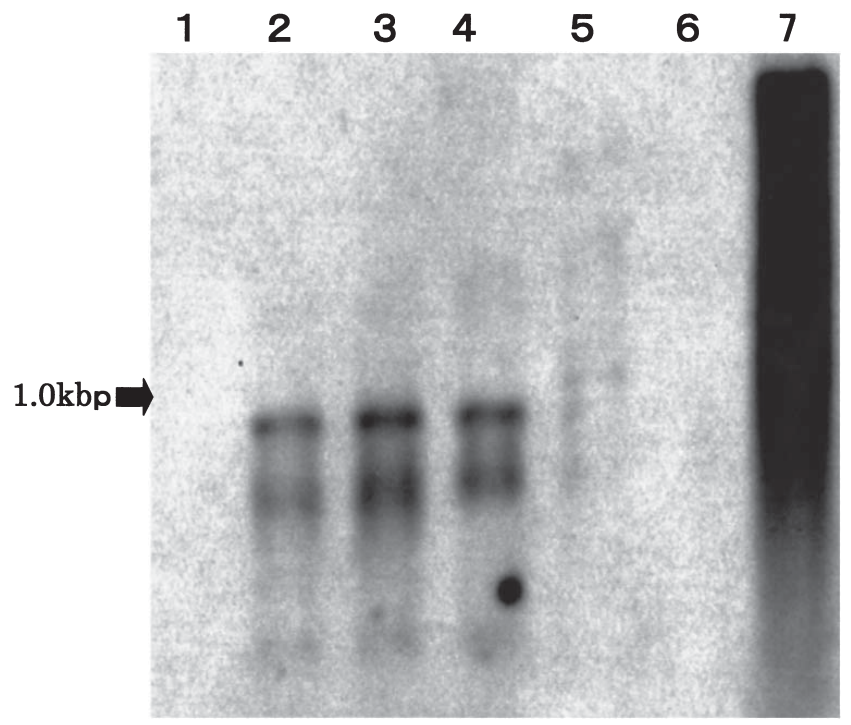

Fig. 4. RNA blot analysis of total RNA from selected resistant transgenic plants that did not show disease symptoms probed with a CP fragment in transformed plants. Lane 1: No. 79; lanes 2 and 3: 2 plants from No. 55; lane 4: one plant from No. 86; 5: one plant from No. 118; 6: non-transformed plant (cv. Jack); and 7: SMV infected plants.
1
2
3
4
5
6
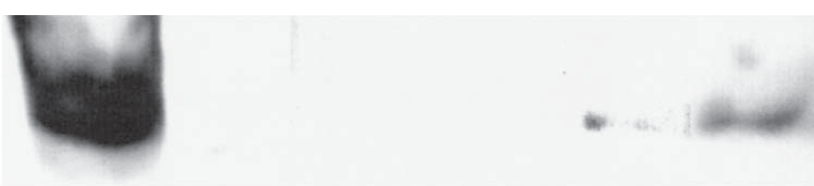

Fig. 5. Western blot analysis of leaf of transformed plants expressing the CP gene. Lane 1: non-transformed plant (cv. Jack) inoculated with strain D of SMV; 2: non-transformed plant; lanes 3 and 4: 2 plants from No. 55; lane 5: one plant from No. 118; and 6: one plant from No. 86 .

\section{Molecular analysis}

Young leaves of 11 transgenic soybean plants had been preserved at minus $80^{\circ} \mathrm{C}$ prior to the mechanical inoculation for the detection of transgene transcript in the $T_{1}$ plants. The transgene transcript of SMV-CP was detected by Northern blot analysis in the resistant plants of the lines Nos. 55, 86, whereas for 118 with faint signal, but not in a susceptible plant No. 79 (Fig. 4).

The transgene product was also detected in lines Nos. 86 and 118 except in line No. 55 by Western blot analysis (Fig. 5).

\section{Discussion}

In this study, we have succeeded to produce transformants introduced with $\mathrm{CP}$ gene of the attenuated virus. These transgenic soybean lines Nos. 55, 86 and 118 showed a high resistance to SMV infection. Its level is as sufficiently practical as the one with the attenuated virus inoculation. 
In recent successful transgenic studies, two types of CP gene-mediated resistant transformant are reported. One is the type transformed with a $\mathrm{CP}$ gene, showing transgene expression, in which transgene product is detectable (Zheng et al. 1997, Lehmann et al. 2003). The other is the one transformed with a CP gene (Kawchuk and Prufer 1999, Hayakawa et al. 1992, Wang et al. 2001) or a modified CP gene (Sinisterra et al. 1999, Sivamani et al. 2002). They show transgene expression to some extent, but transgene product is not detectable in them. SMV resistant transgenic soybean lines Nos. 86 and 118 belong to the former type, and are considered to have obtained the $\mathrm{CP}$-mediated resistance. To the contrary, a line No. 55 belongs to the latter type, and is assumed to have obtained the RNA-mediated resistance, because of the lack of detectable transgene product. Although highly resistant soybean plants to SMV were thus obtained at $\mathrm{T}_{1}$ generation, further studies are necessary to examine the stability of the trait in the progeny and to elucidate the precise mechanism of resistance.

Transgenic soybean lines Nos. 55, 86 and 118 showed high resistance to SMV D and A strains to the same extent as the attenuated SMV-inoculated plants (data for A not shown). As the attenuated SMV has a strong resistance to SMV strains A, B, C, D and E (Kosaka and Fukunishi 1993), transgenic soybean lines Nos. 55, 86, and 118 are also expected to be resistant to SMV strains $B, C$, and E, which remains to be tested.

In many studies to confer crops pathogen-derived transgenic resistance, $\mathrm{CP}$ gene of the original virulent strains is used (Rong et al. 1996, Zheng et al. 1997, Kawchuk and Prufer 1999, Pang et al. 2000, Wang et al. 2001). On the other hand, we avoid to use $\mathrm{CP}$ gene of original virulent strains that gives serious damage to plants themselves, and adopted that of the attenuated viruses. They even show crossprotection to the other virulent strains. Actually the attenuated SMV has been practically used in the soybean field as a virus protector for more than 20 years in Kyoto Prefecture, Japan.

Mottling of seeds is one of the main components of the seed quality issues, and was less than $2 \%$ in our study using the resistant transformant mediated by the $\mathrm{CP}$ gene of the attenuated SMV, whereas that of the original strain N CPmediated transgenic soybean was ranged from 1 to $8 \%$ (Wang et al. 2001). In connection to this, inoculation of the attenuated SMV to soybean plants reduced seed mottling of original SMV-inoculated plants from 71.9 to $6.6 \%$ (Kosaka and Fukunishi 1993). The PDR using the CP gene of the attenuated SMV could also reduce seed mottling by SMV infection as in Fig. 2, and consequently improve soybean seed quality.

In this study, we succeeded to produce two types of SMV resistant transformants by introducing CP gene of the attenuated SMV. The resistance to SMV infection is as sufficiently practical as the one with the attenuated virus inoculation.

\section{Acknowledgements}

We thank Dr. N. Otsubo for his helpful suggestions, Ms. N. Yamagishi for technical assistance and Dr. T. Tsuchizaki for supplying antiserum against SMV. This work was funded by the Kyoto Prefectural Government and the Ministry of Agriculture, Forestry and Fisheries of Japan.

\section{Literature Cited}

Finer,J.J. and A.Nagasawa (1988) Development of an embryogenic suspension culture of soybean (Glycine max Merrill.). Plant Cell Tissue Organ Cult. 15: 125-136.

Fitchen,J.H. and R.N.Beachy (1993) Genetically engineered protection against viruses in transgenic plants. Annu. Rev. Microbiol. 47: 739-763.

Furutani,N. and S.Hidaka (2004) Efficient production of transgenic soybean using a co-transformation method. Breed. Sci. 54: 9198.

Hadidi,A., R.K. Khetarpal and H.Koganezawa (1998) Plant disease control. The American Phytopathological Society Press, St. Paul, Minnesota. $65 \mathrm{p}$.

Hayakawa,T., Y.Zhu, K.Itoh, Y.Kimura, T.Izawa, K.Shimamoto and S.Toriyama (1992) Genetically engineered rice resistant to rice stripe virus, an insect-transmitted virus. Proc. Natl. Acad. Sci. USA 89: 9865-9869.

Jules, J. (1994) Development of virus resistant plants via genetic engineering. Plant Breed. Rev. 12: 47-80.

Kawchuk,L.M. and D.Prufer (1999) Molecular strategies for engineering resistance to potato viruses. Can. J. Plant Pathol. 21: 231-247.

Kosaka,Y. and T.Fukunishi (1993) Attenuated isolates of soybean mosaic virus derived at a low temperature. Plant Disease. 77 : 882-886.

Laemmli,U.K. (1970) Cleavage of structural proteins during the assembly of the head of bacteriophage $T_{4}$. Nature 227: 680-685.

Lehmann,P., C.E.Jenner, E.Kozubek, A.J.Greenland and J.A.Walsh (2003) Coat protein-mediated resistance to Turnip mosaic virus in oilseed rape (Brassica napus). Mol. Breed. 11: 83-94.

Mitsuhara, I., M. Ugaki, H. Hirochika, M.Ohshima, T. Murakami, Y.Gotoh, Y.Katayose, S.Nakamura, R.Honkura, S.Nishimiya, K.Ueno, A.Mochizuki, H.Tanimoto, H.Tsugawa, Y.Otsuki and Y.Ohashi (1996) Efficient promoter cassettes for enhanced expression of foreign genes in dicotyledonous and monocotyledonous plants. Plant Cell Physiol. 37: 49-59.

Namba, S. (1992) Molecular breeding of resistance against potyvirus infection. In "Plant Cell Technology vol. 4". Shujunsha Co., Ltd. Tokyo. p. 101-109 (in Japanese).

Pang, S.Z., F.J.Jan, D.M.Tricoli，P.F.Russell，K.J.Carney，J.S.Hu, M.Fuchs, H.D.Quemada and D.Gonsalves (2000) Resistance to squash mosaic Como virus in transgenic squash plants expressing its coat protein genes. Mol. Breed. 6: 87-93.

Powell-Abel,P., R.S.Nelson, N.DeB.Hoffmann, S.G.Rogers, R.T. Fraley and R.N.Beachy (1986) Delay of disease development in transgenic plants that express the tobacco mosaic virus coat protein gene. Science 232: 738-743.

Rong,D., V.Purcell, G.B.Collin and S.A.Ghabrial (1996) Production of transgenic soybean lines expressing the bean pod mottle virus coat protein precursor gene. Plant Cell Rep. 15: 746-750.

Samoylov, V.M., D.M.Tucker, F.Thibaud-Nissen and W.A.Parrott 
(1998) A liquid-medium-based protocol for rapid regeneration from embryogenic soybean cultures. Plant Cell Rep. 18: 49-54.

Sanford,J.C. and S.A.Johnson (1985) The concept of parasite derived resistance. J. Theor. Biol. 113: 395-405.

Scholthof,K.G., H.B.Scholthof and A.O.Jackson (1993) Control of plant diseases by pathogen-derived resistance in transgenic plants. Plant Physiol. 102: 7-12.

Shigemori,I. (1991) Studies on the breeding on soybeans for the resistance to soybean mosaic virus (SMV). Bull. Nagano Chushin Agric. Exp. Stn. 10: 1-60 (in Japanese).

Sinclair,J.B. (1984) Compendium of Soybean Diseases. The American Phytopathological Society Press. p. 29-30.

Sinisterra, X.H., J.E.Polston, A.M. Abouzid and E.Hiebert (1999) Tobacco plants transformed with a modified coat protein of tomato mottle begomovirus show resistance to virus infection.
Phytopathology 89: 701-706.

Sivamani,E., C.W.Brey, L.E.Talbert, M.A.Young, W.E.Dyer, W.K. Kaniewski and R.Qu (2002) Resistance to wheat streak mosaic virus in transgenic wheat engineered with the viral coat protein gene. Transgenic Res. 11:31-41.

Tsuchizaki,T. and T.Omura (1987) Relationships among bean common virus, blackeye cowpea mosaic virus, and soybean mosaic virus. Ann. Phytopathol. Soc. Japan. 53: 478-488.

Wang, X., A.L. Eggenberger, F.W. Nutter Jr. and J.H.Hill (2001) Pathogen-derived transgenic resistance to soybean mosaic virus in soybean. Mol. Breed. 8: 119-127.

Zheng,H.H., Y.Li, Z.H.Yu, W.Li and M.Y.Chen (1997) Recovery of transgenic rice plants expressing the rice dwarf virus outer coat protein gene (S8). Theor. Appl. Genet. 94: 522-527. 